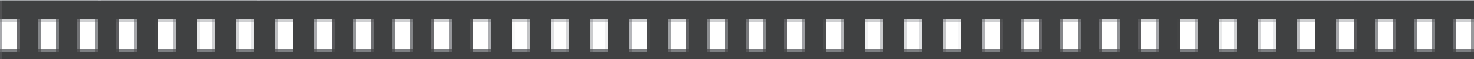

\author{
Entrevista: \\ Iatã Cannabrava
}

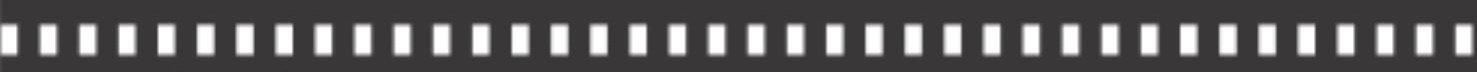

Paulo César Boni 


\section{Macunaíma forjado no caldeirão latino-americano}

\section{Paulo César Boni*}

O fotógrafo, curador e produtor cultural paulista Iatã Cannabrava foi eleito, por aclamação, o primeiro presidente da recém-fundada Rede de Produtores Culturais da Fotografia no Brasil. Consolidada no final de maio, num encontro que reuniu cerca de 150 fotógrafos, curadores, pesquisadores, professores, produtores e agitadores culturais em Brasília, a RPCFB, ou simplesmente Rede, como já ficou batizada popularmente, está em fase de registro para adquirir legalmente o status de pessoa jurídica sem fins lucrativos.

Dos seis aos 18 anos, Iatã viveu no Peru, Bolívia, Panamá e Cuba, acompanhando seus pais no exílio. Por essa e outras experiências, costuma dizer que é "um pouco de tudo" em termos étnicos e culturais. Profissionalmente, diz que é multifuncional: atua como fotógrafo, curador, organizador de eventos, agitador cultural. "Até escrevo e edito de vez em quando", arrisca. Nos últimos anos, tem se dedicado ao "fazer cultural", um ramo que, segundo ele, juntou todas as características de seu trabalho. Iatã costuma brincar que é uma espécie de "Macunaíma, forjado no caldeirão étnico latino-americano".

Estabelecido profissionalmente na Vila Madalena, em São Paulo, também ministra aulas e workshops para sobrevier. É representado pela Galeria Babel, mas também vende fotografias em um Banco de imagens, o Samba Foto. Porém, em volume e importância, seu trabalho, hoje, está mais voltado para a produção cultural. Neste momento, organiza o Paraty em Foco, que será realizado em setembro, e o Fórum Latino-Americano de Fotografia, que será realizado em outubro, em São Paulo.

\footnotetext{
* Doutor em Ciências da Comunicação pela Universidade de São Paulo. Coordenador do Mestrado em Comunicação da Universidade Estadual de Londrina. Editor da revista Discursos Fotográficos.
} 


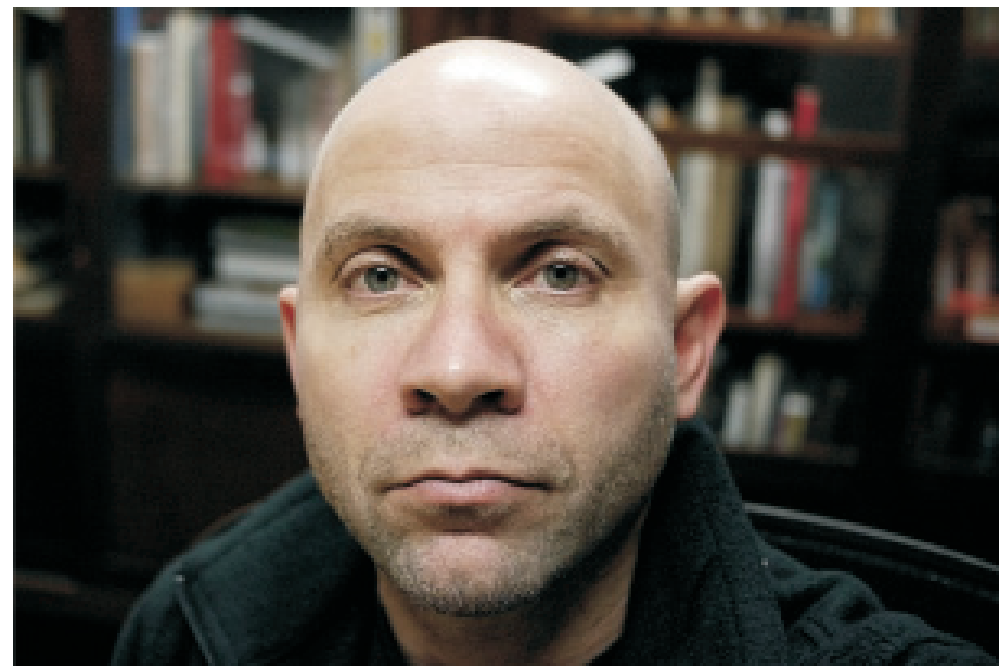

Iatã Cannabrava

Fotografia: Iatã Cannabrava (Autorretrato)

\section{Entrevista}

Paulo Boni - O que é exatamente a Rede de Produtores Culturais da Fotografia no Brasil?

Iatã Cannabrava - É uma apresentação do fazer cultural da fotografia brasileira. Não é uma rede nem uma associação de fotógrafos, é uma associação de criadores, de pessoas com iniciativas, de realizadores que organizam e orientam os criadores. É uma rede maior de outras redes menores. Com isso, temos escolas, cursos livres, galerias, produtores culturais, festivais e encontros. E mais. Estamos criando núcleos. Temos realizadores e projetos, ou seja, estamos formalizando uma rede de realizadores e de projetos, independente do realizador ou do tamanho do projeto. Para nós, alguém que escreve uma tese é um realizador, assim como quem coordena um curso também é um realizador. No entanto, quem fotografa é um autor. Então, a Rede não é uma associação só de autores, criadores ou realizadores. É, sim, uma associação dos gestores do processo de criação. 
Paulo Boni-Ou seja, a Rede pretende aglutinar e sinergizar todos os interesses voltados à fotografia?

Iatã Cannabrava - Esse é o objetivo básico da Rede. E ela surge num período em que a fotografia vive um momento especial. Há uma explosão de festivais voltados à fotografia, ela ganha espaço nas galerias e museus. Os cursos formais e informais (livres) se multiplicam pelo país. O número de praticantes cresce verticalmente; as publicações pululam em progressão geométrica. Nunca se produziu e publicou tanta fotografia como nos dias atuais. Ela tem sido cada vez mais utilizada como um instrumento de comunicação da sociedade. E, nesse momento, a Rede surge como um fórum balizador, uma alternativa de interrelacionamento entre os diversos setores do fazer cultural da fotografia e do relacionamento destes com os poderes constituídos. É trabalhoso, difícil e sem garantias de resultado você conversar com o poder público, as grandes empresas ou outros financiadores do fazer cultural de forma desorganizada. Então, o que propomos é organizar a interlocução dos produtores e gestores culturais da fotografia com os poderes constituídos. Em suma, queremos ser uma associação de gestores culturais - responsáveis pelo fazer cultural da fotografia no Brasil - focada e em sintonia com os poderes constituídos e outros agentes financiadores da cultura.

Paulo Boni - O evento de Brasília representou o parto da Rede, mas ela é o resultado palpável de uma trajetória evolutiva. Quando e como ela, de fato, começou a ser gestada?

Iatã Cannabrava - Nesse modelo que estamos consolidando agora, seu surgimento é recente e seu crescimento foi meteórico. O embrião deu-se no último festival Paraty em Foco, em setembro de 2009. Nós, organizadores, percebemos a participação de uma série de produtores culturais, convidados por "n" razões, e outros não convidados, mas que foram por conta própria. Percebemos o potencial dessa gente toda reunida e decidimos fazer o primeiro encontro de agitadores culturais da fotografia no Brasil. Para nossa surpresa, foi uma reunião incrível. Estavam presentes seis representantes do Ministério da Cultura e uns trinta agitadores culturais. 
E, o melhor de tudo, como não se tratava de um encontro de classe, e sim de classes, a conversa fluiu. Boas ideias foram discutidas e, pela primeira vez, cogitou-se a possibilidade de fundarmos um espaço de convergência de interesses. Assim, surgiu a Carta de Paraty, solicitando a criação de um canal de comunicação para discutir políticas públicas com o governo federal. O Ministério da Cultura nos recebeu prontamente. Em dezembro de 2009, uma comissão designada esteve em Brasília e conversou com o ministro Juca Ferreira. Em janeiro de 2010 esta mesma comissão conversou com o Sérgio Mamberti, presidente da Funarte. Em maio, já estávamos em Brasília, consolidando a Rede, num encontro realizado com total apoio e participação do governo federal.

Paulo Boni - Antes de Paraty, nada havia sido feito nesse sentido?

Iatã Cannabrava - Pelo contrário: uma porção de eventos já havia sido realizada. Não com essa finalidade específica, mas que contribuíram - e muito - para a organização da classe fotográfica. Não podemos deixar de citar as Semanas Nacionais de Fotografia, promovidas pela Funarte nas décadas de 70 e 80 , verdadeiro processo de maturação do pensar e do fazer fotográfico brasileiro. Ou seja, a Rede nasceu no momento histórico correto, um momento ímpar de maturidade da fotografia brasileira.

Paulo Boni - Então, em síntese, só estava faltando alguém para organizar os fragmentos de iniciativas isoladas e assumir a frente desse processo?

Iatã Cannabrava - Mais ou menos isso.

Paulo Boni-O que a Rede irá significar para a fotografia brasileira? Haverá uma mudança do que era até 2010 e o do que será daí para frente?

Iatã Cannabrava - Primeiro, é preciso ficar claro que a Rede será um processo de constantes ajustes. Será um processo que objetiva possibilitar a concretização dos projetos que propõe e das políticas públicas que irá discutir com as autoridades constituídas. Ou seja, nada será feito 
ou terá resultados do dia para noite. Também é preciso lembrar que estamos no fim do mandato presencial e, com a mudança na Presidência da República, pode haver mudanças significativas na forma de condução da cultura no país. Nesse momento, o que posso afirmar é que existe vontade política, um entrosamento importante com o Ministério da Cultura e, com isso, a Rede vive nesse momento, uma amizade cultural positiva, uma aproximação cultural profícua. Agora, é preciso lembrar que trabalhar com políticas públicas não é falar de imediatismos. É preciso consolidar caminhos. Neste sentido, estamos discutindo a criação de uma fototeca ou de uma rede de fototecas, pensando na preservação da memória da fotografia brasileira, algo parecido com a Cinemateca Brasileira, acrescido de pitadas de experiência das fototecas mexicanas, que são descentralizadas. Em suma, há muita coisa para ser vista.

Paulo Boni - Publicações não seriam uma eficiente forma de popularização e preservação da memória fotográfica brasileira?

Iatã Cannabrava-Claro que sim. Estamos pensando em projetos que incentivem o mercado editorial. Mas precisamos responder perguntas. O que é o mercado editorial? Onde está? Quem estudou o assunto? Quais são as demandas? Pela ordem, vamos primeiro estudar o projeto da(s) fototeca(s). Ambas, fototecas e mercado editorial serão trabalhos hercúleos que demandarão tempo, relacionamento político, projetos e coisa e tal. Então, voltando e respondendo a pergunta anterior, não acredito que a fotografia será medida antes e depois da Rede, como se ela fosse um marco, uma espécie de on e off. Não será um divisor tão claro de águas, será uma espécie de encontro de águas amazônicas, que demoram um pouco para se misturar, em alguns momentos você não sabe se está no rio Negro ou no Amazonas. Ou seja, acho que é um processo mais difuso, mas, com certeza, não tem volta.

Paulo Boni - A Rede pretende ser uma geradora de políticas, uma norteadora de procedimentos, ou ambos? 
Iatã Cannabrava - Muito já se discutiu sobre isso na internet ou pessoalmente, mas o que está se consolidando é a ideia de sermos articuladores, ou seja, articular a classe produtora, a sociedade realizadora e organizadora, e os poderes constituídos. Essa será a principal função fomentadora da Rede, que terá também um importante papel na difusão e democratização das atividades desenvolvidas pelos seus filiados. A produção fotográfica do Norte, por exemplo, é pouca conhecida. Talvez a Rede possa desenvolver ações de fomentos para tornar a fotografia do Norte, e das outras regiões também, é claro, mais conhecida. Mas não acredito que ela venha a ser uma produtora. Fala-se muito na publicação de coleções nacionais e regionais de fotografia, mas eu não acredito que a Rede vire uma editora, por exemplo, pois ela estaria concorrendo com alguns de seus próprios membros, que são editores. Ela também não irá se transformar numa escola de fotografia, pois também estaria concorrendo com alguns de seus membros, que são professores ou organizadores de cursos livres e formais. Então, insisto, o papel da Rede é promover a articulação entre interesses.

Paulo Boni - Neste momento, em que está se formalizando, registrando seus documentos em cartório, enfim, se legalizando, a Rede já definiu suas prioridades?

Iatã Cannabrava - Bom, até maio de 2011, nossa tarefa fundamental é concluir o que foi iniciado para a realização do próprio encontro em Brasília, ou seja, formalizar a criação da Rede e fazer o mapeamento de quem somos, informação imprescindível para quem está querendo começar com o pé direito.

Paulo Boni-Quem somos, quantos somos, onde estamos e o que queremos?

Iatã Cannabrava - Quem somos, quantos somos, onde estamos, o que queremos e economicamente o que significamos. Estamos fazendo essa pesquisa. Em breve o site entrará no ar de forma experimental e solicitaremos aos membros da Rede que nos ajudem nessa pesquisa. Em 
princípio, o modo de informação de dados será parecido com formato do Wikipedia, do wiki. Vamos usar o que a ferramenta do wiki tem de bom. Vamos ter as informações moderadas e editadas. Mas quem irá preencher as informações sobre Londrina serão os londrinenses participantes da Rede. Serão eles que irão informar que haverá um curso na cidade, uma exposição ou qualquer outra iniciativa social com a fotografia. Os membros irão receber suas senhas de acesso e, com elas, poderão alimentar o sistema. Com isso, poderemos realizar a pesquisa em tempo recorde. Enquanto isso não fica pronto, estamos trabalhando em outras frentes. Como o Ministério da Cultura anunciou recursos na ordem de 30 milhões de reais específicos para projetos de fotografia este ano, através do Fundo Nacional de Cultura, estamos estudando em que áreas cotas desse montante devem ser priorizadas. Assim, temos duas prioridades: terminar a pesquisa e aproveitar esse momento propício para nortear as políticas públicas mais imediatas.

Paulo Boni - A Rede irá prestar assessoria jurídica para seus associados no que diz respeito a direitos autorais e uso de imagens?

Iatã Cannabrava - Consideramos esta questão como crucial. Solicitamos aos membros da Rede que se manifestassem na consulta pública que se encerrou em julho. Alguns se manifestaram, dando sugestões de ajustes na nova lei de Direitos Autorais que deve ser aprovada ainda este ano ou, no mais tardar, em 2011. É importante o segmento fotografia se mobilizar em prol de uma lei que resguarde seus interesses, pois outros segmentos das artes, como a música e o mercado editorial já se manifestaram, reclamaram, reivindicaram e obtiveram bons resultados. O Ministério da Cultura está empenhado em regularizar essa questão da melhor forma possível, tanto que está promovendo discussões em várias cidades do país. Aqui em São Paulo, no início de julho, houve um debate promovido pelo Itaú Cultural com a presença do responsável pela área de direitos autorais do MinC (Ministério da Cultura), Marcos Souza. É importante que sejam discutidos, acertados e regularizados os direitos autorais do fotógrafo, 
principalmente o que diz respeito ao direito autoral das obras que aparecem inseridas na obra do fotógrafo, quando você fotografa uma estátua, uma escultura, um prédio que tem uma obra assinada por um arquiteto. Essas dificuldades do "direito conexo" é uma das coisas que mais preocupa a classe e não está sendo devidamente discutida porque não diz respeito a outros setores, como a música. O cinema e a fotografia são os únicos interessados em discutir e definir essa questão. Agora, quanto a prestar assistência ou serviços de assessoria, como você perguntou, eu acho que a Rede não deve prestar esses serviços, ela deve, sim, ser uma mediadora, fazer a ponte entre a parte interessada e aqueles que podem prestar esses serviços. Se abarcar todos esses serviços, a Rede poderá inchar demais.

Paulo Boni - Como a Rede se sustentará? Os associados terão que contribuir com mensalidades ou anuidades?

Iatã Cannabrava - Boa pergunta. A gente já conversou sobre isso em Brasília, já demos uma cutucada no pessoal para analisar e avaliar a reação de cada um. Atualmente, a Rede se sustenta com um projeto aprovado pelo Ministério da Cultura para a realização da pesquisa de quem somos, quantos somos, onde estamos e o que pretendemos. Assim, esse projeto banca financeiramente três ou quatro pessoas diretamente envolvidas com essa pesquisa. São recursos parcos, mas, por enquanto, a Rede é pequena e dá para ir tocando, mas tanto o projeto quanto os recursos estão previstos até maio de 2011. Depois disso, só Deus sabe. Pode ser que a gente continue com essa vocação de aprovar pequenos projetos que continuem a sustentá-la, mas creio que não haverá como escapar da cobrança de uma pequena mensalidade que responda pelo dia-a-dia de uma secretaria e pela alimentação constante do site.

Paulo Boni-Qual o período limite para a finalização da pesquisa? Iatã Cannabrava - Pretendemos encerrá-la até março ou abril de 2011. Até esse período, as pessoas envolvidas neste trabalho estão cobertas financeiramente com as verbas do projeto. 
Paulo Boni -A Rede pretende vasculhar, na internet, editais de financiamento de órgãos e/ou agências de fomento e repassá-los para seus associados?

Iatã Cannabrava - Obviamente, a internet será a grande ferramenta de comunicação e assessoramento da Rede. Teremos um portal e a eficiência desse portal irá depender muito do interesse e participação dos filiados, afinal boa parte do trabalho será voluntário, ou seja, todos poderão disponibilizar informações sobre editais, exposições, encontros, simpósios, cursos etc. Iremos contratar profissionais para manter o portal funcionando, pois ele não será um simples site, nem um blog, mas um portal mesmo, onde você entra e encontra dicas sobre tudo: agenda, editais, links etc. Você poderá manter contato com os demais filiados, falar de editais, colocar suas dúvidas no fórum de discussão, debater sobre a difusão da fotografia, consultar as câmaras setoriais (todos os GTs Grupos de Trabalho do encontro em Brasília foram transformados em câmaras setoriais) e outros serviços mais. De repente, por exemplo, você escreve para o portal dizendo que tem dúvidas no preenchimento do formulário de um edital da Petrobrás e talvez haja algum especialista ao seu lado, na sua cidade, na sua região, ou mesmo do outro lado do país, que poderá auxiliá-lo via internet.

Paulo Boni - E se o interessado não encontrar um "colega" especialista no portal, a Rede irá prestar assessoria técnica para a elaboração de projetos?

Iatã Cannabrava - Num primeiro momento, não. A contratação desse tipo de profissional iria inchar sua estrutura, gerar custos e, por enquanto, ainda nem sabemos com certeza como ela irá se manter.

Paulo Boni - Você acredita que haverá solidariedade por parte dos filiados na democratização de conhecimentos e informações pela Rede?

Iatã Cannabrava - Espero que haja, sim, solidariedade. Se os filiados considerarem o portal como um prestador de serviços e ficarem 
esperando que alguém, por decreto ou por dinheiro, faça tudo, a coisa não irá funcionar. Eu já vi um monte sites incríveis e bons projetos morrerem por conta das pessoas ficarem esperando por paternalismo. Mas, no sentido contrário, a vantagem da internet é o dinamismo, a vontade de partilhar. Nela as pessoas as pessoas entram, postam informações, compartilham. É claro que uma ou duas pessoas não darão conta de descobrir e democratizar todos os editais, mas 150 pessoas de olho nos editais será outra realidade. Poderemos ter, inclusive, editais municipais com participação nacional.

Paulo Boni - Hoje, há cerca de 150 filiados. A questão é: qualquer fotógrafo, professor, produtor cultural, editor de revistas, coordenador de curso pode se filiar à Rede?

Iatã Cannabrava - A Rede está aberta a qualquer iniciativa do fazer cultural que atinja a terceiros. A explicação é meio complexa. O que eu quero dizer é que não queremos ser uma caixa estanque nem burocratizar excessivamente. Em suma, para entender o que é a Rede, temos que pensar muito em iniciativas culturais no campo da fotografia. Nelas estão, por exemplo, fotógrafos, curadores, produtores e agitadores culturais, diretores de escola, professores de fotografia, editores que trabalhem no campo cultural da fotografia e outros profissionais. Os 150 que estiveram em Brasília já tiveram sua filiação aprovada em assembleia. As solicitações de novas filiações precisam ser apresentadas por algum filiado. Com a apresentação, a diretoria executiva aprova precariamente a filiação. Mas só quem tem soberania para aprovar os novos pedidos são as assembleias extraordinárias, realizadas uma vez por ano, e as ordinárias, realizadas a cada dois anos.

Paulo Boni: Tem havido procura por novas filiações?

Iatã Cannabrava - Entre junho e julho tivemos mais de trinta pedidos de filiação. É importante destacar que se, por exemplo, algum produtor cultural achar que tem o perfil de promotor cultural da fotografia, que procure algum filiado e diga: "Eu quero fazer parte da Rede." 
Paulo Boni - A Rede planeja a realização de grandes eventos para ganhar visibilidade ou será uma entidade de trabalho e ações silenciosas?

Iatã Cannabrava - Acho que totalmente silenciosa não dá para ser. Afinal o papel do articulador tem que estar em constante visibilidade. Temos que estar na memória dos gestores da venda da cultura, sejam eles públicos ou privados. Antes de alguém constituir uma mesa para debater direitos autorais, por exemplo, será preciso consultar a Rede...

Paulo Boni - Recentemente o Itaú Cultural promoveu uma mesa para discutir direitos autorais, em São Paulo. A Rede foi consultada?

Iatã Cannabrava - Não, porque ela ainda não é suficientemente conhecida. É por isso que não podemos ser muito silenciosos. Temos que fazer algum barulho, um som alto. Para tanto, pode ser que seja necessário a execução de projetos culturais para que isso fique evidente. Recentemente, o Ricardo Rezende, que era diretor dos projetos de artes visuais da Funarte saiu do cargo. Os artistas visuais, imediatamente, fizeram circular uma petição, pela internet, solicitando que o Ministério da Cultura consulte o setor para substituí-lo. É um movimento válido. Muita gente da Rede assinou essa petição, ou seja, já estamos mostrando a cara. Provavelmente, em curto espaço de tempo, ela seja nacionalmente conhecida, respeitada e com poder de influência. É preciso aproveitar esse bom momento de diálogo com o governo atual, ganhar visibilidade, conquistar respeito e passar a influenciar as políticas públicas para o setor. Já que há esse diálogo com o Ministério da Cultura, vamos tentar participar da indicação de dirigentes para o setor. Com essas e outras atividades, a Rede começa a selar um discurso de participação e compromisso com a diversidade e a qualidade do fazer cultural no campo da fotografia.

Paulo Boni - Você usa muito o termo Rede. Depois de tudo legalizado, será utilizado RPCFB (Rede de Produtores Culturais da Fotografia no Brasil) ou simplesmente Rede? 
Iatã Cannabrava - Acho que isso não tem mais volta... Desde antes do evento em Brasília todos falavam em Rede. Pegou. É fácil de lembrar e de pronunciar; é muito sonoro. Pegou.

Paulo Boni - A Rede pretende trabalhar para a regulamentação da profissão de fotógrafo?

Iatã Cannabrava - Creio que não. Afinal, a quem interessa a regulamentação da profissão? Tenho minhas dúvidas se isso não interessa apenas a um setor da tecnocracia pública. Eu, particularmente, não consigo imaginar qual será o ganho do fotógrafo a regulamentação da profissão. Já me explicaram isso, já tentaram me convencer, mas eu não consigo entender o diferencial, não consigo ver vantagem nenhuma nisso. Hoje, a maioria dos fotógrafos são constituídos como pessoas jurídicas. A lei permite e até incentiva que você tenha uma empresa fotográfica dentro do "super simples", modalidade econômica que poucos países do mundo têm de forma tão simples e generosa. Muitos colegas se queixam erroneamente das vantagens oferecidas pelo governo. Hoje, o imposto é único e varia de $6 \%$ a $12 \%$, em média. Na frieza da realidade, trata-se de uma relação de custo-e-benefício muito vantajosa com o fisco.

Paulo Boni - Então, hoje, é muito mais fácil, rápido e vantajoso o sujeito se transformar em uma pessoa jurídica?

Iatã Cannabrava-Sim. Mas, mais importante que isso: me parece fundamental pensar a fotografia como um campo do pensamento, e não como uma profissão. Não me parece imprescindível que um jornalista que trabalhe com fotografia seja profissionalizado como fotógrafo. Que seja jornalista mesmo. Não vejo necessidade de o Ministério do Trabalho regulamentar a profissão de fotógrafo. Sinceramente, não vejo o que a gente vai ganhar com isso.

Paulo Boni - Pegando o gancho... se um jornalista não precisa se profissionalizar como fotógrafo, o mesmo deverá valer para as outras profissões. Esta dedução é só para justificar a pergunta. A Rede pretende 
ser uma associação fechada, só com fotógrafos, produtores e agitadores culturais da área da fotografia, ou ser mais ampla e receber gente de outras áreas, desde que tenham alguma ligação com a fotografia?

Iatã Cannabrava - Alguns de nossos membros são curadores e nunca fizeram, profissionalmente, uma fotografia na vida. $\mathrm{O}$ mesmo vale para donos de galeria e gestores de eventos. Ou seja, tem muita gente que não é exatamente fotógrafo, mas tem uma ligação com o fazer cultural da fotografia, uma ligação eminente com a fotografia, e isso é o que mais importa. A Rede não deixa de ser uma associação de classe, nascida para defender os interesses de uma classe, como espaços, direitos e recursos. Por exemplo, ela vai se empenhar para divulgar e consolidar eventos relacionados com a fotografia, como o FestFotoPoa, de Porto Alegre, o Paraty em Foco, de Paraty, o Floripa na Foto, de Florianópolis, o FotoRio, do Rio de Janeiro, o Agosto da Fotografia, de Salvador, a Semana de Fotografia do Recife, o deVERcidade, de Fortaleza, o Foto Pirenópolis, de Goiás, o Fotolink, de Londrina, e tantos outros. Esses eventos são importantes para reunir fotógrafos e discutir a fotografia, mas não estão economicamente consolidados. Assim, um ano podemos ter todos, outro ano apenas alguns. Acho legal trabalhar pela consolidação econômica e qualitativa de todos os eventos ligados ao fazer cultural da fotografia. Esse tipo de trabalho justifica a existência de uma associação corporativa como a Rede, né?!

Paulo Boni-Tivemos um bom exemplo no Paraná que foi a Bienal de Curitiba. Enquanto havia dinheiro, foi um sucesso, quando a fonte secou (recursos do governo do estado), o evento se perdeu.

Iatã Cannabrava - O próprio Paraty em Foco, esse ano, está no limite. Pensamos até em cancelá-lo. A realidade é que nem tudo que interessa à sociedade interessa ao mercado. E vice-versa: nem tudo que interessa a mercado interessa à sociedade. Portanto, precisamos de bons produtos culturais e bons patrocinadores, sejam eles públicos ou privados. Essa convergência de interesses é fundamental. E para que ela exista, precisamos de qualidade no fazer cultural e interesse dos patrocinadores, 
pois é muito difícil um bom produto cultural sobreviver sem viabilidade financeira.

\section{Paulo Boni-Como é ser presidente da Rede?}

Iatã Cannabrava - É uma pergunta que parece simples, mas é estranha. Eu custo a acreditar que sou o presidente da Rede. Demoro a entender o que isso significa. Se tivesse 30 anos de idade, veria isso com orgulho e coisa e tal, mas na maturidade dos 47 anos, eu penso: "Nossa, que encrenca eu comprei!' O fato é que há muito trabalho a fazer e eu fico me perguntando se terei tempo para fazer tudo isso...

Paulo Boni-Alguma coisa mais, para finalizar?

Iatã Cannabrava - Acho que falamos o mais importante. Para não cometer nenhuma injustiça, quero reforçar que a Rede é uma associação de classe, nascida de um modelo, o do Paraty em Foco, mas que tem um vasto histórico anterior, desde as Semanas Nacionais de Fotografia, promovidas pela Funarte, ou seja, ela é uma prova da eficiência dos festivais.

Paulo Boni - Na última edição da revista há um artigo, do Alberto Viana, que faz uma recuperação histórica dos festivais e outras manifestações culturais da fotografia em Curitiba. Se todas as cidades fizessem o mesmo, teríamos uma importante linha norteadora para a recuperação, preservação e consolidação da memória da fotografia no Brasil. A Rede tem alguma estratégia de ação para isso?

Iatã Cannabrava - Ainda não está devidamente formulada e formalizada, mas é uma de suas propostas. E o começo será a publicação de um livro com os resultados da pesquisa que estamos fazendo, pois o projeto prevê uma publicação. E mais: é preciso consolidar a memória além dos festivais. As exposições e as galerias, por exemplo. Os cursos livres têm uma importância fundamental; as universidades, então, nem se diga... Precisamos, além dos festivais, recuperar a memória de todos os segmentos do fazer cultural da fotografia. 
Paulo Boni - Você sempre fala em cursos livres e ensino formal separadamente. Há possibilidade de aproximação dessas iniciativas no fazer cultural da fotografia?

Iatã Cannabrava - Claro. Vocês mesmo, na Universidade Estadual de Londrina, têm o ensino formal da fotografia, mas eu sei que já levaram o Cláudio Feijó, o Clício Barroso, o Emídio Luisi, o Sérgio Sade e outros fotógrafos para ministrarem cursos livres dentro dessa proposta formal. Isso é legal porque aproxima os profissionais do mercado de trabalho da escola e a escola do mercado de trabalho, ou seja, a formalidade da escola com a informalidade dos fotógrafos profissionais. Há uma entrevista do Maurício Lissovsky no blog do II Fórum Latino-Americano de Fotografia (http://www.forumfoto.org.br/pt/2010/07/mauricio-lissovsky) que ressalta a importância dessa aproximação. Assim, o estudante não sai da academia com uma visão surreal do mercado, e, ao mesmo tempo, a academia contribui com o aprofundamento dos conhecimentos teóricos, humanistas, éticos e estéticos da fotografia. 